\title{
Improving Food Safety Within the Dairy Chain: An Application of Conjoint Analysis
}

\author{
N. I. Valeeva, ${ }^{1,2,3}$ M. P. M. Meuwissen, ${ }^{2}$ A. G. J. M. Oude Lansink, ${ }^{1}$ \\ and R. B. M. Huirne $e^{1,2}$ \\ ${ }^{1}$ Farm Management Group, and \\ ${ }^{2}$ Institute for Risk Management in Agriculture, Wageningen University, \\ Hollandseweg 1, $6706 \mathrm{KN}$, Wageningen, The Netherlands \\ ${ }^{3}$ Faculty of Economics, Moscow Timiryazev Agricultural Academy, \\ Timiryazevskaya 49, 127550 Moscow, Russia
}

\begin{abstract}
This study determined the relative importance of attributes of food safety improvement in the production chain of fluid pasteurized milk. The chain was divided into 4 blocks: "feed" (compound feed production and its transport), "farm" (dairy farm), "dairy processing" (transport and processing of raw milk, delivery of pasteurized milk), and "consumer" (retailer/catering establishment and pasteurized milk consumption). The concept of food safety improvement focused on 2 main groups of hazards: chemical (antibiotics and dioxin) and microbiological (Salmonella, Escherichia coli, Mycobacterium paratuberculosis, and Staphylococcus aureus). Adaptive conjoint analysis was used to investigate food safety experts' perceptions of the attributes' importance. Preference data from individual experts $(n=24)$ on 101 attributes along the chain were collected in a computer-interactive mode. Experts perceived the attributes from the "feed" and "farm" blocks as being more vital for controlling the chemical hazards; whereas the attributes from the "farm" and "dairy processing" were considered more vital for controlling the microbiological hazards. For the chemical hazards, "identification of treated cows" and "quality assurance system of compound feed manufacturers" were considered the most important attributes. For the microbiological hazards, these were "manure supply source" and "action in salmonellosis and M. paratuberculosis cases". The rather high importance of attributes relating to quality assurance and traceability systems of the chain participants indicates that participants look for food safety assurance from the preceding participants. This information has substantial decision-making implications for private
\end{abstract}

Received April 26, 2004.

Accepted December 11, 2004.

Corresponding author: Natalia Valeeva; e-mail: natasha.valeeva @wur.nl. businesses along the chain and for the government regarding the food safety improvement of fluid pasteurized milk.

(Key words: food safety, conjoint analysis, dairy chain, fluid milk)

Abbreviation key: ACA = adaptive conjoint analysis .

\section{INTRODUCTION}

The complex and interlinked nature of food safety hazards and food production as a whole has been widely recognized. An integrated approach to controlling food safety throughout the entire food chain ("farm to table") has become an important issue in guaranteeing a greater food safety level for consumer products (Stefan, 1997; European Commission, 2000; Valeeva et al., 2004). In line with these ideas about food safety, a number of countries have developed and introduced new regulations to assure food safety at different stages of the food production chain. Most of these regulations stipulate that improving food safety should focus not only on assuring safe food production within a single stage but also on assuring other links relating to this stage. For instance, the British Retail Consortium Technical Standard requires Hazard Analysis Critical Control Point adoption for companies supplying retailer food products. The Supply Chain Management System is one example for ensuring the quality of farm milk in the Netherlands to meet the demands of the dairy processing industry. This system requires compliance with the specified criteria for animal health, feeding, hygiene, and environmental aspects. Another example is the Integrated Chain Control system used in the Dutch meat sector. Within such a system, every link in the chain-from the farmer through to the point of sale-guarantees to meet requirements with regard to quality, origin, and safety of meat, and is able to exchange information about animals and meat. 
For each chain participant, a goal of food safety improvement can be expressed as meeting the existing acceptable levels of hazards and minimizing the probability that their products are identified as the cause of an illness (Ollinger and Ballenger, 2003). To achieve this goal, different concepts of food safety improvement consisting of various attributes are available for chain participants. Attributes involve prevention, elimination, or reduction of food safety hazards by means of a set of actions and activities or, in other words, control measures (Valeeva et al., 2004). Given the many potential and emerging hazards along the chain, it is of practical importance to prioritize attributes-it is not possible to deal equally with them all at the same time. Unfortunately, no knowledge is available regarding how to find the most important attributes in the chain, i.e., attributes that require extra attention by chain participants. Therefore, the objective of this study was to quantify the importance of attributes for improving food safety in the chain. The dairy production chain for fluid pasteurized milk was used as a case study. Although dairy products are deemed one of the safest classes of food, there is considerable concern, because hazards originating from dairy products could affect a large number of consumers. Potential problems are associated with the presence of microbiological hazards (e.g., Listeria monocytogenes, Salmonella, Staph. aureus, E. coli) and chemical hazards (e.g., natural toxins, drug residues, food additives). Among other dairy products, such as cheese, ice cream, nonfat dry milk, and raw milk, fluid pasteurized milk is a product at risk (Gould et al., 2000).

A large number of attributes contribute to the improvement of food safety along the chain. Many of these attributes are measured in different units and are not directly comparable with each other. In addition, for attributes that require a lot of administration and auditing (such as "monitoring"), it is difficult to quantify their exact contribution. For these reasons, experts' judgments were considered the only way to obtain consistent quantitative information on the importance of the attributes. Several techniques are available for eliciting experts' judgments. This paper demonstrates the use of adaptive conjoint analysis (ACA) to investigate the food safety experts' perceptions of the importance of the attributes.

\section{MATERIALS AND METHODS}

\section{Adaptive Conjoint Analysis}

In general, conjoint analysis has received considerable academic and industry attention as a major set of techniques for measuring consumers' tradeoffs among multi-attributed products (Green and Srinivasan, 1990). The conjoint model is a multi-attribute model, which assumes that consumers purchase products (e.g., apple) based on their characteristics, or attributes (e.g., flavor) and that each attribute may have 2 or more levels (e.g., sweet, tart, bitter). Then the individual's utility for a multi-attributed product concept, U, can be expressed in a simple way as a sum of utilities for its attributes, $u\left(a_{j}\right)$, that is:

$$
\mathrm{U}=\mathrm{u}\left(\mathrm{a}_{1}\right)+\mathrm{u}\left(\mathrm{a}_{2}\right)+\ldots+\mathrm{u}\left(\mathrm{a}_{\mathrm{n}}\right)
$$

where $\mathrm{U}=$ utility for a product concept, and $\mathrm{u}\left(\mathrm{a}_{\mathrm{j}}\right)=$ utility for level of the level of an attribute $a_{j}(j=1$ to $n)$.

Conjoint analysis relies on the ability of respondents to evaluate a product concept by combining the separate amounts of utility provided by each attribute of the concept. A set of hypothetical concepts is constructed, where each product concept-a so-called profile-stands for a specific combination of attribute levels. Respondents are asked to estimate their overall preference for each profile. The basic aim is to determine the attribute that the respondents prefer most. Then conjoint analysis estimates the value of each of the attributes using the choices that respondents make along product concepts that vary in systematic ways. Several computer programs are available for performing this analysis. The utilities, or part-worths, for each single level of each attribute are the result of such a process. These utilities can be used to determine the relative importance of each attribute in developing a new product concept; these are provided by the spread in utilities between the highest- and lowestrated levels of the attribute (Churchill, 1999). For a comprehensive overview of the development in conjoint analysis and related methods, see Green and Srinivasan (1990) and Churchill (1999).

In this study, the ACA method is applied. Adaptive conjoint analysis combines aspects of composition (self-explicated task, i.e., respondents rate the importance of the difference between the best and worst levels, separately for each attribute) and decomposition approaches (conjoint task, i.e., respondents indicate preference intensity judgments for paired partial profiles) (Wittink et al., 1994). It obtains the final preference function coefficients by pooling the 2 types of data (Wittink and Bergestuen, 1999). The ACA system collects individual respondents' preference data in a computer-interactive mode. The use of a personal computer allows ACA to customize the partial profile characteristics based on each respondent's self-explicated data. This implies that during the conjoint task, the respondents are interviewed in detail about only those attributes that they regard as being more important. 
Part-worths for these more important attributes are then refined (in a "Bayesian" updating sense) through a series of graded paired comparisons where the respondent's previous answers are used at each step to select the next paired comparison question so as to provide most information. This allows ACA to investigate many attributes without asking the respondents to deal with too much information on the computer screen at any one time (Green and Srinivasan, 1990).

\section{The Dairy Chain}

The current research includes all the independent actors that are able to affect the food safety level of the end product of the whole dairy chain, i.e., the consumed fluid pasteurized milk. In particular, the chain includes a compound feed production stage, a dairy farm stage, a processing factory stage, a retailer and catering stage, and the actual consumption of pasteurized milk. Transportation between the stages is also considered, i.e., transport of compound feed to the dairy farm, transport of raw milk to the processing factory, and delivery of pasteurized milk to the sale unit (retailer/catering establishment).

The stages are combined into 4 major blocks, that is "feed" (compound feed production and its transport), "farm" (dairy farm), "dairy processing" (transport and processing of raw milk, delivery of pasteurized milk), and "consumer" (retailer/catering establishment and pasteurized milk consumption).

The concept of food safety improvement for the fluid pasteurized milk chain that was studied focuses on the 2 important groups of food safety hazards: chemical and microbiological. In particular, the group of chemical hazards includes antibiotics and dioxin, and the group of microbiological hazards includes Salmonella, E. coli, Staph. aureus, and Mycobacterium paratuberculosis. Hazards were selected after literature research (Cullor, 1995a; Collins, 1997; Cullor, 1997; Gould et al., 2000; Rowe et al., 2000; Mathews et al., 2001) and consultation with experts from the dairy industry, research organizations, and regulatory authorities.

\section{Survey Design}

In this study, the design of the survey was determined by 2 facts. First, there were no experts who had a complete and adequate overview of various attribute impacts on food safety along the entire dairy chain. Second, the need to consider different aspects of improving food safety revealed a great number of attributes along the chain, which had to be balanced against the limited number of attributes (maximum $=$
30) that could be included in a single ACA questionnaire. Consequently, it was decided first to consider the chain split into the 4 blocks introduced in the previous section; and then, to integrate experts' perceptions of attributes' importances per block into those for the whole chain. The questionnaire for the survey consisted of a computer-based part and a paper-based part.

The computer-based part contained ACA tasks to explore the relative importance of various food safety attributes to improving food safety. Based on a review of the scientific literature on the control of the considered hazards (Cullor, 1995b; Sischo et al., 1997; Benedictus et al., 2000; Veling et al., 2002), current regulations, and individual consultations with experts on each of the 4 blocks, a concept of food safety improvement was subdivided into 101 key attributes along the chain. The choice of the attributes was driven by the need to describe adequately the concept of improving food safety. In particular, the attributes mirrored production steps, which may influence food safety in the chain. Some food safety attributes were relevant for the control of both chemical and microbiological hazards. Examples of such attributes for the farm block are "identification of treated cows" and "best farm practices". From the 101 selected attributes, 50 attributes were relevant for chemical aspects of food safety improvement and 95 for microbiological aspects. The concept involved single- and multiple-effect attributes. Single-effect attributes focus on the control of one of the considered hazards. For example, at the farm stage, the attribute "separation of the calf from mother cow after birth" is mainly applied for the control of $M$. paratuberculosis. Multiple-effect attributes designed for the control of one hazard may affect other hazards as well, but perhaps not to the same degree (Jensen and Unnevehr, 2000). This makes the assessment of the total effect of these attributes difficult. For instance, manure can be the source of contamination for Salmonella or E. coli, so the attributes meant for manure control will influence both of these hazards.

The "feed" block included 27 attributes considering compound feed for dairy cattle as the end product. The "farm" block with raw milk as the end product consisted of 32 attributes. The "dairy processing" and "consumer" blocks comprised 23 and 19 attributes, respectively, implicating packaged fluid pasteurized milk as the end product.

Each attribute consisted of a number of mutually independent levels (2 to 5 ) representing control measures differently affecting food safety. For instance, for the "farm" block, the attribute "acquisition of cattle" comprised the 3 levels, or measures: a) acquisition of cattle whose herd health status is known, b) acquisi- 
tion of cattle whose herd health status is unknown, c) no acquisition of cattle, i.e., having a "closed herd". To ensure appropriateness of the selected attributes and their levels to a particular block, experts from the block were asked to verify them.

In total, 8 computerized ACA questionnaires were composed (ACA User Manual System, 2002). In other words, 2 cases regarding chemical and microbiological food safety improvement were developed for each of the 4 blocks of the chain.

Throughout the questionnaires, the respondents were asked to focus on food safety aspects of the attributes, leaving other aspects, such as costs, out of consideration. In addition, handouts were provided to specify the requirements included in attributes of large scope such as "general/personal hygiene conditions on the farm".

The paper-based part of the questionnaire was used to integrate individual block results into chain results. A point allocation method was used to determine the importance of each block for overall food safety improvement along the chain. In other words, respondents were asked to divide a total of 100 points among the blocks regarding the need for implementing additional food safety measures to reach the highest food safety level of fluid pasteurized milk. Respondents completed this questionnaire with respect to chemical and microbiological hazards.

To ensure that questions in both computer-based and paper-based parts were transparent and that respondents easily became familiar with the applied techniques, a questionnaire pretest was conducted. As the number of respondents was limited (see later), no experts were selected for the pretest sample. Instead, 8 staff members were chosen from the Farm Management Group of Wageningen University, who were familiar with the subject of food safety in the dairy chain.

\section{Analytical Procedure of ACA Questionnaire}

Each ACA questionnaire included a series of questions combined into 4 sections. The first 2 sections were used to estimate approximate preferences for attributes and their levels (self-explicated task). In the first section, the respondent rated the levels within attributes for preference using a 7 -point scale $(1=$ least preferred, $7=$ most preferred). In the second section, the respondent indicated on a 7 -point scale $(1=$ not important, 7 = extremely important) the importance of differences between the attribute levels that the respondent had stated as "most preferred" and "least preferred" in the first section.

The third section refined the estimated preferences through adapted paired-comparison trade-off ques- tions (conjoint task). In each question, 2 hypothetical food safety concepts differing by 2 or 3 attributes were shown to the respondent. Using a 9-point scale, the respondent expressed the preference and its strength for one of the proposed concepts ( $1=$ strong preference for one concept, 9 = strong preference for the other concept). Pairings were drawn up in such a way that respondents distinguished very little difference between the concepts, which were constructed based on the respondents' preferences obtained from the previous 2 sections. With each answer, the respondent's utilities were updated.

These steps of the ACA process can be formalized in terms of an additive, main-effects part-worth model for each individual respondent that combines, via OLS regression, self-explicated data on attribute-level preference, and attribute importance ratings with graded paired-comparison preferences for partial profiles of food safety concepts (Green et al., 1991). Details of the model of the ACA process, complex regression layout and updating part-worth procedure are provided by Jonson (1987), Green et al. (1991), and Jonson (1991).

The final section investigated the consistency of the ACA model predictions of the set of preference evaluations given by each respondent. Five validation profiles of food safety improvement concepts were composed. Profiles consisted of 5 attributes determined as being most important in the earlier sections. For each validation profile, the respondent indicated a likelihood of implementing the concept if it were possible immediately $(0=$ definitely would not implement, $100=$ definitely would implement). For each respondent, the fit $\left(\mathrm{R}^{2}\right)$ between scores of likelihood estimated by the ACA model and actual scores of validation profiles was determined.

\section{Data Collection}

Two workshops were organized to collect the data needed for this study. To represent the entire chain, the invitation for evening workshops was sent to 76 individuals in July 2002. The individuals work in regulatory authorities, industries, research, and organizations in the work field such as the Dutch Farmer Organization in the Netherlands. They are considered food safety experts for a particular part of the dairy chain. The invitation contained a cover letter, a short description of the study, a list of invited persons, and a reply form. In September, recipients were mailed a reminder letter and another copy of the reply form.

In October 2002, 19 respondents took part in the workshops. Through additional personal interviews, which were conducted from February to August 2003, using exactly the same survey design, the number of 
respondents was extended to 24 . Based on prior knowledge, the respondents were subdivided into 4 groups representing all blocks of the chain: "feed" $=4(16.7 \%)$, "farm" = $13(54.2 \%)$, "dairy processing" $=5(20.8 \%)$, and "consumer" $=2(8.3 \%)$.

Each workshop, lasting two-and-one-half hours, started with a short introduction to the topic, describing implied blocks of the dairy chain and hazards, and the technical explanations related to the questionnaire, paying special attention to the computer-based part. Then the participants had 2 computer-based sessions for chemical and microbiological cases respectively, followed by the paper-based session. Each participant worked individually with a personal computer at his/her own speed, so that the influence from others was limited.

\section{Data Analysis}

Adaptive conjoint analysis was used to estimate preference functions of food safety improvement attributes for each case of the block. The survey data collected via the computer-based part of the questionnaire were analyzed by the ACA software (ACA User Manual System, 2002). The part-worths for each single level of each attribute were estimated for respondents individually. The relative importance of each attribute was derived in ACA for each individual by obtaining the difference between the part-worths of the most preferred and the least preferred attribute levels, and expressed in terms of percentage (Churchill, 1999). Results per block are expressed as mean values of relative attribute importances. Paired-samples $t$-test was used to compare differences between means of attributes' importances within a block. In cases when assumption of normality for a difference between 2 means of attributes' importances was rejected, the Wilcoxon signed-rank test was used (Field, 2002). The differences were considered statistically significant if the $P$ value was less or equal to a level of $10 \%$.

Kendall's coefficient of concordance $W$ was used to examine inter-respondent reliability for each case of the block. In general, the coefficient of concordance is a function of the variance in the sums of ranks. It is used to evaluate the association among 3 or more sets of rankings (Churchill, 1999). In this analysis, Kendall's coefficient of concordance $W$ checks the association among the rankings of the attributes' importances provided by the ACA model.

The survey data obtained in the paper-based part of the questionnaire were used to compute the relative weight of each block with respect to the need of the implementation of additional measures throughout the dairy chain to reach a higher food safety level of fluid pasteurized milk. This weight was called "chain weight" and was defined for chemical and microbiological cases. The average chain weight of each block was expressed as overall mean for all respondents, that is, each respondent had an equal weight.

\section{RESULTS AND DISCUSSION}

\section{Analysis per Block}

Tables 1 to 4 present the average relative importance of the attributes according to experts' opinions for "feed", "farm", "dairy processing", and "consumer" blocks respectively. The higher relative importance of an attribute implies that experts believe more efforts should be paid to that attribute. In each table, the results for chemical and microbiological food safety improvement are outlined. The attributes are presented in chronological order of the production process within each block.

From Table 1, it appears that in the chemical case of the "feed" block, the attributes "procedures and instructions for compound feed production" $(6.84 \%)$ and "quality assurance system of feed ingredient manufacturers" $(6.74 \%)$ are perceived to be more important. In the microbiological case, it seems that "feed ingredient identification and traceability" (9.08\%), "quality assurance system of feed ingredient manufacturers" (6.03\%) are the more important ones. "Adequate cleaning and disinfection of transport vehicles" $(5.37 \%)$ and "adequate conditions of feed ingredient storage and intake" (5.34\%) follow these in importance. According to Table 1 , in the "feed" block there are no attributes that are perceived to be extremely important. The top 3 attributes account for only 19.55 and $20.48 \%$ of the total importance of the 21 and 23 attributes included in the chemical and microbiological cases, respectively. However, in both cases there was no significant difference between means of attributes' importances $(P>$ $0.10)$. On the other hand, "quality assurance system of feed ingredient manufacturers" tends to be important in both cases. This is also true for other attributes relating to feed ingredients. These results indicate that incoming feed ingredients might be the vital point with respect to the considered chemical and microbiological hazards for the "feed" block of the dairy production chain.

For the "farm" block, from the 13 attributes included for the chemical case, "identification of treated cows" (11.22\%), and "quality assurance system of compound feed manufacturers" $(10.50 \%)$ are slightly more important attributes (Table 2). For 30 attributes involved 
Table 1. Mean relative importance (rankings in parentheses) of food safety attributes for the "feed" block (\%).

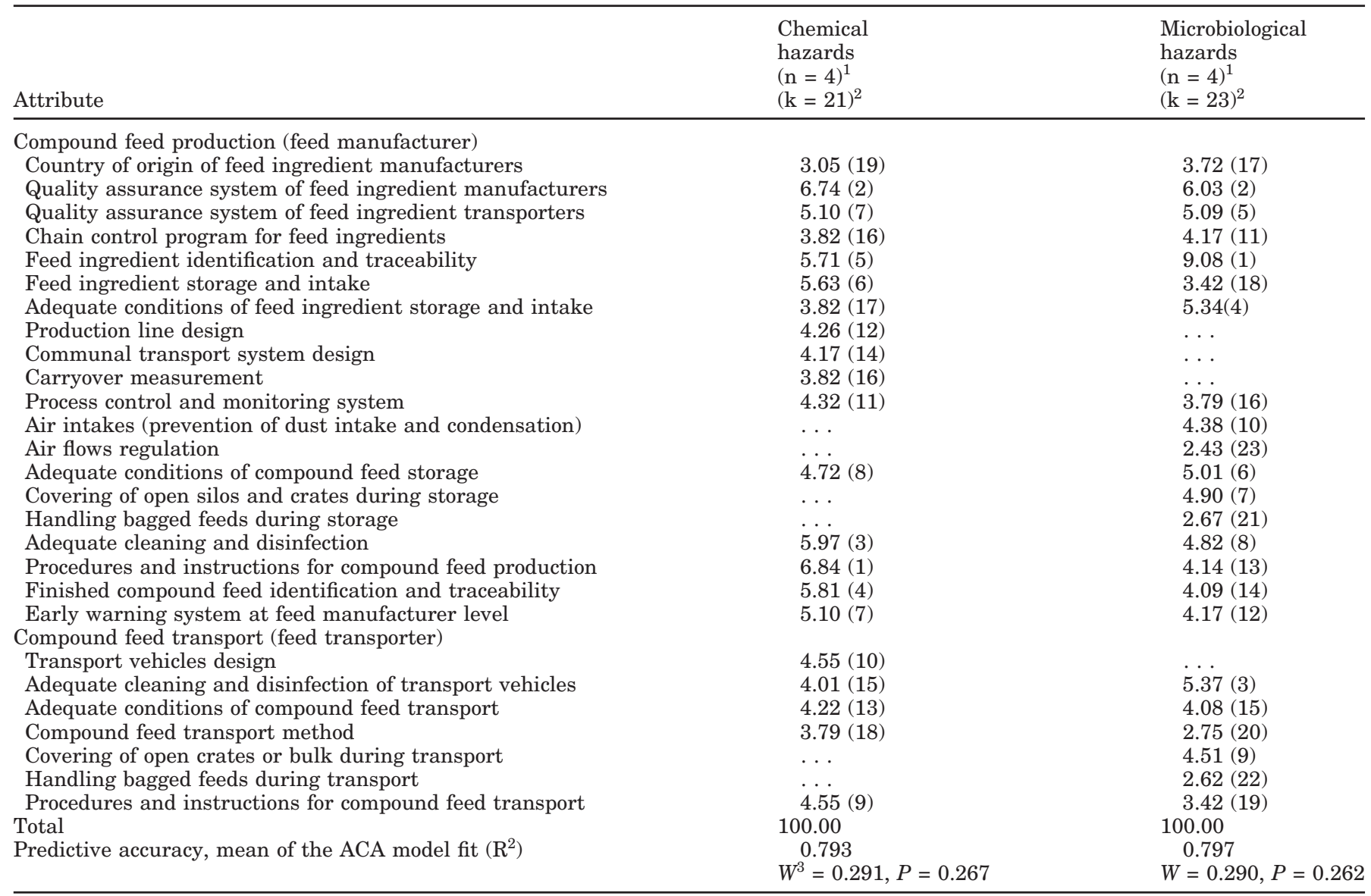

\footnotetext{
${ }^{1} \mathrm{n}$ represents the number of respondents per block.

${ }^{2} \mathrm{k}$ represents the number of attributes per case.

${ }^{3} \mathrm{~W}$ represents the Kendall's coefficient of concordance $(P=$ Monte Carlo $P)$.
}

in the microbiological case, these are "manure supply source" (4.31\%), "action in salmonellosis and M. paratuberculosis cases" (4.25\%), and "acquisition of cattle" $(4.20 \%)$. In both cases for some attributes, results detect significant differences between means of attributes' importances $(P \leq 0.05$ and $P \leq 0.10)$. From the results it can be seen that many attributes are more or less equally important. This could mean that in the current situation on the farm it is rather important to consider improvement at several points simultaneously. Particularly, this could be true for microbiological hazards. However, the results indicate that attributes that are important for the control of chemical hazards ( 2 highest ranked attributes) are not the most important for the control of microbiological hazards (rank 14 and 11, respectively).

According to Table 3, for the "dairy processing" block, "sourcing raw milk" (19.27\%), "delivered raw milk identification and traceability" (18.63\%), and "procedures and instructions for raw milk processing" (14.30\%) at the dairy processing factory are perceived as the more important attributes among the 7 included in the chemical case; however, the differences between means of attributes' importances are not statistically different $(P>0.10)$. The results show that the 2 attributes referring to incoming raw milk account for $37.9 \%$ of importance. This would suggest that with respect to chemical hazards, for dairy processors, the receipt of raw milk is the main control point for taking additional measures in the current situation. For the microbiological case, among the 23 attributes, the more important attributes include "finished product identification and traceability" (5.97\%), "location of sealing equipment" (5.96\%), and "maintenance of the equipment and leakage prevention" $(5.62 \%)$. In general, although there are many equally important attributes, attributes related to hygiene practice appear to be slightly more important. Examples include "adequate cleaning and disinfection" for both raw milk transport (5.21\%) and raw milk processing (5.07\%), "procedures and instructions for raw 
Table 2. Mean relative importance (rankings in parentheses) of food safety attributes for the "farm" block (\%).

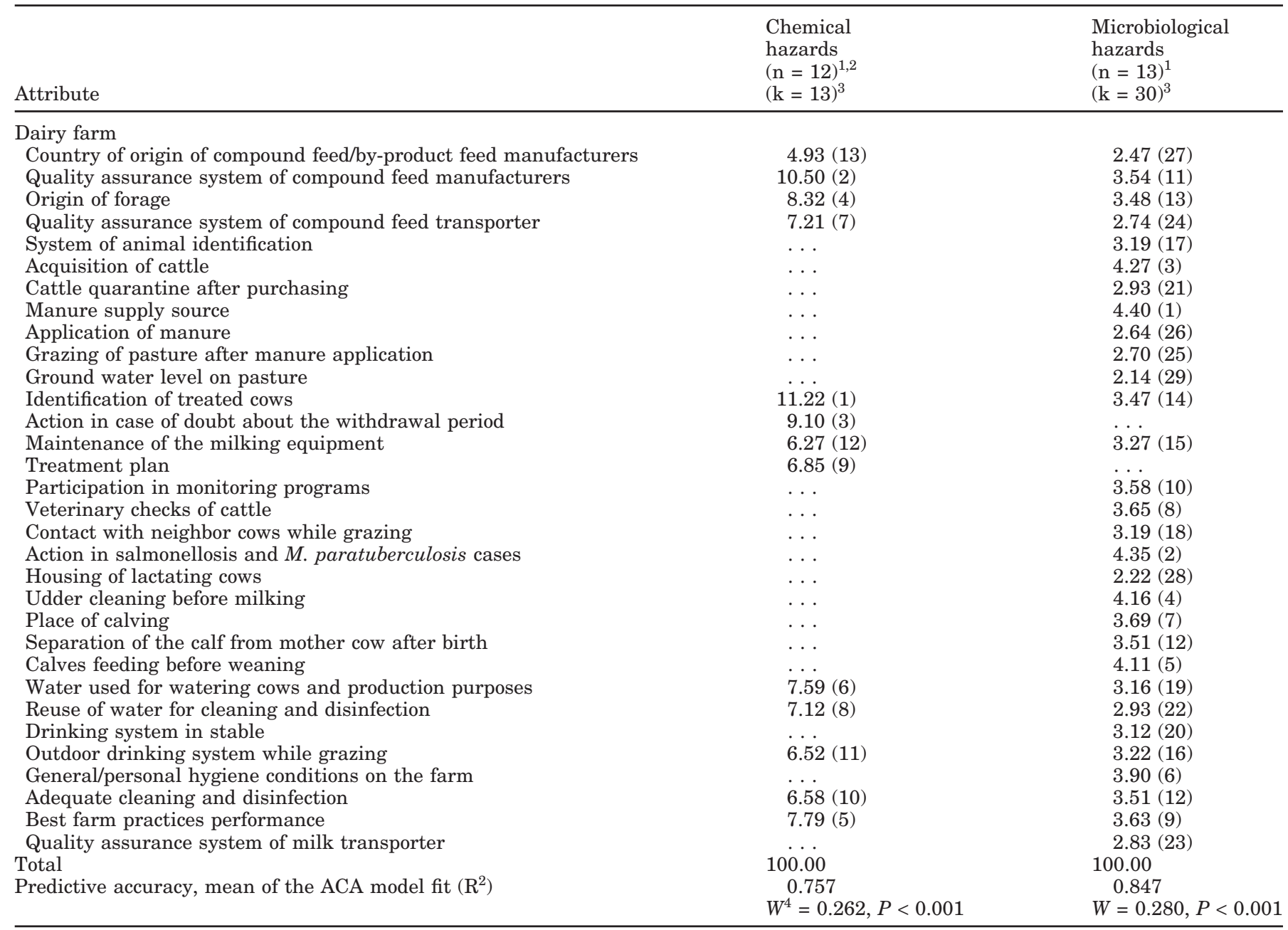

${ }^{1} \mathrm{n}$ represents the number of respondents per block.

${ }^{2}$ One respondent was removed from the analysis due to a mistake made while estimating validation profiles.

${ }^{3} \mathrm{k}$ represents the number of attributes per case.

${ }^{4} W$ represents the Kendall's coefficient of concordance $(P=$ Monte Carlo $P)$.

milk processing" (5.01\%), and "procedures and instructions for raw milk transport" (4.67\%). For a few attributes in the microbiological case, the differences between means of attributes' importances are significantly different $(P \leq 0.05$ and $P \leq 0.10)$.

As can be seen from Table 4, for the "consumer" block "quality assurance system of pasteurized milk manufacturers" (32.27\%), "chain control program for pasteurized milk" $(13.71 \%)$ at the retailer/catering establishment level, and "quality assurance system of pasteurized milk sell units" (17.19\%) for consumption at home seem to be more important attributes among 9 attributes involved in the chemical case. For 19 attributes included in the microbiological case, these are "quality assurance system of pasteurized milk manufacturers" (7.67\%), "maintenance of the equipment" $(7.26 \%)$ for retailer/catering establishment, and "storage of pasteurized milk" (7.56\%) at home. However, in both cases the differences between means of attributes' importances are not statistically significant $(P>0.10)$. These results would indicate that for the considered end product (fluid pasteurized milk) attributes relating to the product suppliers tend to be more important for retailer/ catering establishments than attributes relating to their own performance in both the chemical and microbiological cases. It would also seem that the respondents believe that consumers' decisions (what consumers actually do but it cannot be checked) with respect to buying and storing the product are essential in chemical and microbiological cases, respectively.

Results for the accuracy of ACA models at individual level show that the average fit of the estimated models 
Table 3. Mean relative importance (rankings in parentheses) of food safety attributes for the "dairy processing" block (\%).

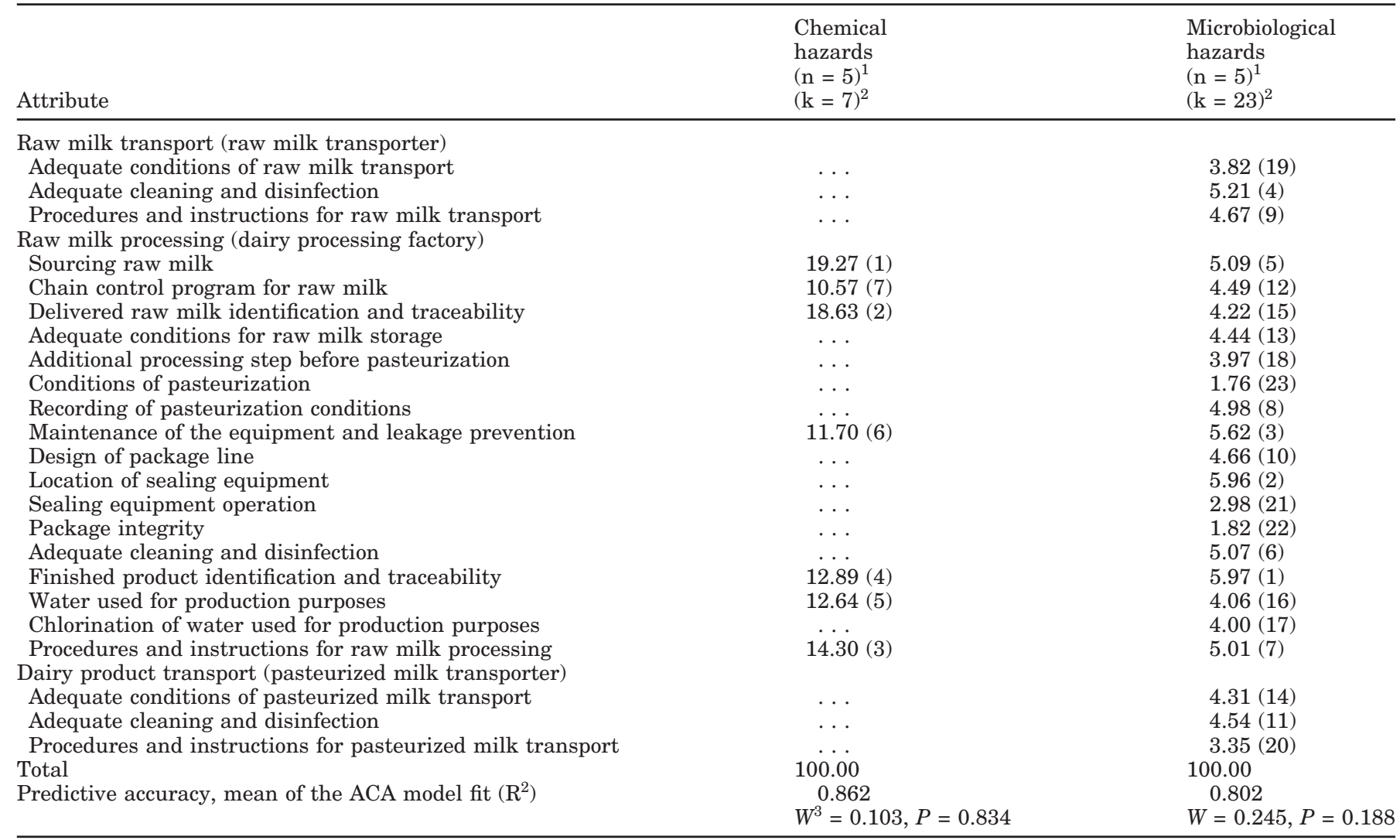

${ }^{1} \mathrm{n}$ represents the number of respondents per block.

${ }^{2} \mathrm{k}$ represents the number of attributes per case.

${ }^{3} \mathrm{~W}$ represents the Kendall's coefficient of concordance $(P=$ Monte Carlo $P)$.

$\left(\mathrm{R}^{2}\right)$ for each block is rather good. It varies from 0.757 ("farm" block) to 0.802 ("dairy processing" block) for chemical cases, and from 0.797 ("feed" block) to 0.888 ("consumer" block) for microbiological cases. These results mean that the explanatory power of the estimated models is adequate. In addition, these results indicate that the respondents were consistent in the evaluation of food safety improvement attributes $\left(\mathrm{R}^{2}>0.6\right.$ ) (Huber et al., 1991). Additional evidence of respondents' consistency-including time to complete survey, patterned answers to the paired-comparison questions, reversals in the utilities-did not reveal inconsistency in respondents' evaluations either. As a result, there was no need to exclude respondents from the further analysis.

The values of Kendall's coefficient of concordance $W$ suggest that there is a significant but relatively not strong agreement among the respondents' rankings only for chemical $(W=0.262, P<0.001)$ and microbiological ( $W=0.280, P<0.001)$ cases of the "farm" block (Tables 1 to 4). This implies that the respondents of this block are fairly applying the same standards in evaluating the food safety improvement.

\section{Relative Weight per Block}

Table 5 presents the average chain weights of each block with respect to chemical and microbiological cases. The chain weights indicate that the "feed" (45.83\%) and "farm" (37.29\%) blocks are significantly more important for implementing additional measures to control the considered chemical hazards $(P \leq 0.05)$. With respect to microbiological hazards, the "farm" (39.37\%) and "dairy processing" (26.46\%) blocks are perceived to be more important than "feed" (14.08\%) and "consumer" (20.08\%) blocks $(P \leq 0.05)$. Furthermore, as can be seen from the table, for chemical hazards, respondents assigned importance scores that resulted in quite similar ordinal rankings for each block of the chain (W $=0.371, P=0.038$ ). However, this was not the case with regard to microbiological hazards.

In addition, in the case of examination with respect to microbiological hazards, results show that respondents from the considered blocks perceive the relative weight of each block rather differently (Table 5). Whereas experts from the "feed" (53.75\%) and "farm" (43.85\%) 
Table 4. Mean relative importance (rankings in parentheses) of food safety attributes for the "consumer" block (\%).

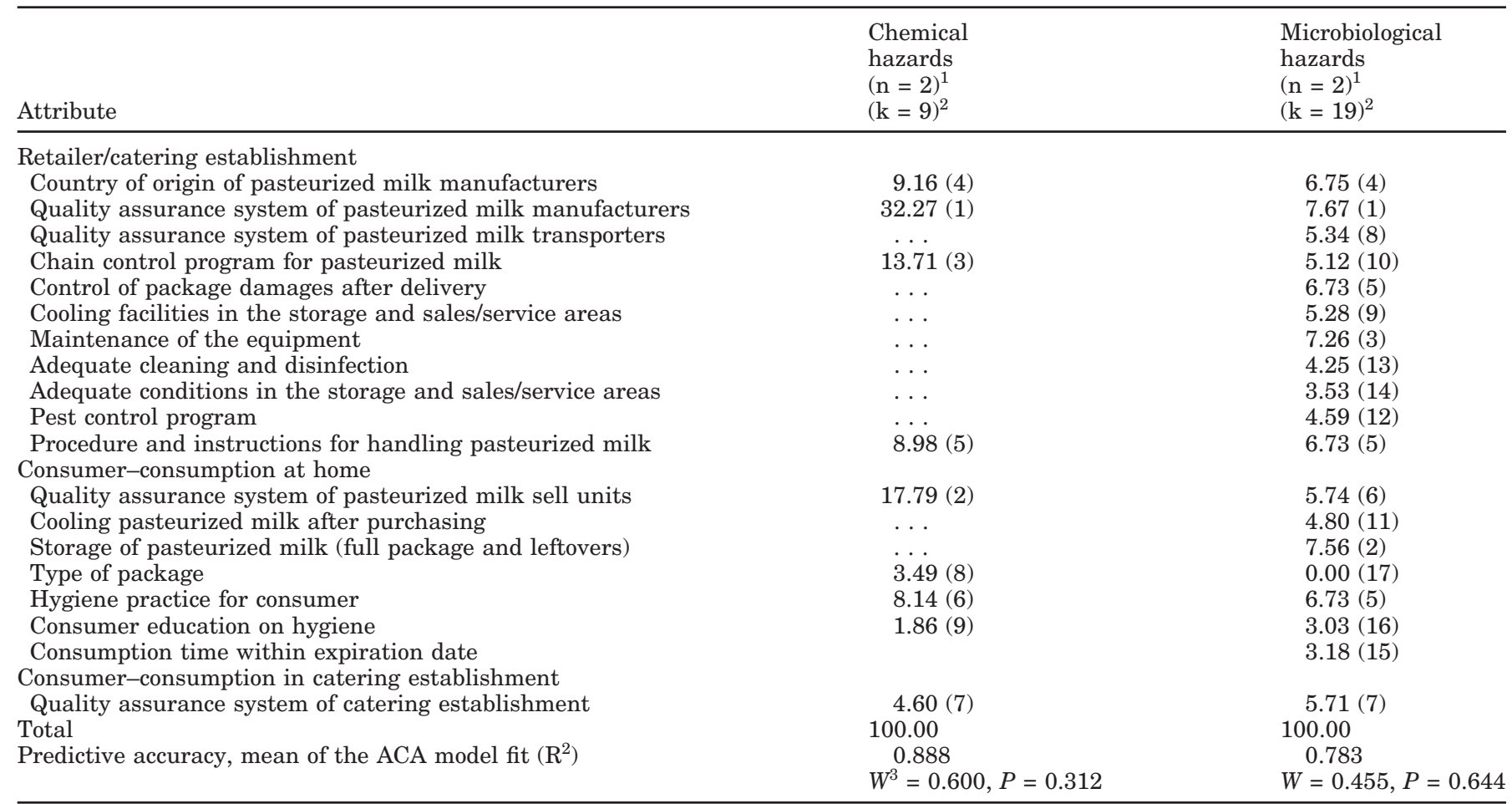

${ }^{1} \mathrm{n}$ represents the number of respondents per block.

${ }^{2} \mathrm{k}$ represents the number of attributes per case.

${ }^{3} \mathrm{~W}$ represents the Kendall's coefficient of concordance $(P=$ Monte Carlo $P)$.

blocks judge the "farm" block most important with respect to the implementation of additional measures to control these hazards, experts from the "dairy processing" and "consumer" blocks assign the highest weight to the "consumer" (33\%) and "dairy processing"
(32.5\%) blocks, respectively. However, with respect to the chemical hazards, experts from the "feed", "dairy processing", and "consumer" blocks agree on the importance order for all blocks, whereas "farmer" block experts valued "farm" block as most important (43.08\%).

Table 5. Chain weights of individual blocks with respect to overall food safety improvement (\%).

\begin{tabular}{|c|c|c|c|c|c|}
\hline & \multicolumn{4}{|c|}{ Mean per block } & \multirow{2}{*}{ Overall mean } \\
\hline & & & Dairy & & \\
\hline & $\begin{array}{l}\text { Feed } \\
\text { experts } \\
(\mathrm{n}=4)^{1}\end{array}$ & $\begin{array}{l}\text { Farm } \\
\text { experts } \\
(\mathrm{n}=13)^{1}\end{array}$ & $\begin{array}{l}\text { processing } \\
\text { experts } \\
(\mathrm{n}=5)^{1}\end{array}$ & $\begin{array}{l}\text { Consumer } \\
\text { experts } \\
(\mathrm{n}=2)^{1}\end{array}$ & $\begin{array}{l}\text { Chain } \\
\text { weight } \\
(\mathrm{n}=24)^{1}\end{array}$ \\
\hline \multicolumn{5}{|l|}{ Chemical hazards } & $W^{2}=0.371, P=0.038$ \\
\hline Feed & 52.50 & 40.00 & 48.00 & 65.00 & $45.83^{\mathrm{a}}$ \\
\hline Farm & 35.00 & 43.08 & 28.00 & 27.50 & $37.29^{\mathrm{a}}$ \\
\hline Dairy processing & 10.00 & 15.23 & 17.00 & 6.50 & 14.00 \\
\hline Consumer & 2.50 & 1.69 & 7.00 & 1.00 & 2.88 \\
\hline Total & 100.00 & 100.00 & 100.00 & 100.00 & 100.00 \\
\hline \multicolumn{5}{|l|}{ Microbiological hazards } & $W=0.216, P=0.682$ \\
\hline Feed & 13.75 & 10.62 & 19.00 & 25.00 & $14.08^{\mathrm{a}}$ \\
\hline Farm & 53.75 & 43.85 & 22.00 & 25.00 & $39.38^{\mathrm{b}}$ \\
\hline Dairy processing & 18.75 & 28.07 & 26.00 & 32.50 & $26.46^{\mathrm{bc}}$ \\
\hline Consumer & 13.75 & 17.46 & 33.00 & 17.50 & $20.08^{\mathrm{ac}}$ \\
\hline Total & 100.00 & 100.00 & 100.00 & 100.00 & 100.00 \\
\hline
\end{tabular}

${ }^{\mathrm{a}, \mathrm{b}, \mathrm{c}}$ Means within a column with different superscripts are significantly different $(P \leq 0.05)$.

${ }^{1} \mathrm{n}$ represents the number of respondents per group.

${ }^{2} W$ represents the Kendall's coefficient of concordance $(P=$ Monte Carlo $P$ ). 
Table 6. The 15 food safety attributes with the highest relative importance (rankings in parentheses) along the dairy production chain for chemical and microbiological cases. ${ }^{1}$

\begin{tabular}{|c|c|c|}
\hline Attribute & $\begin{array}{l}\text { Relative } \\
\text { importance, \% }\end{array}$ & Block \\
\hline \multicolumn{3}{|l|}{ Chemical hazards $(\mathrm{k}=50)^{1}$} \\
\hline Identification of treated cows & $4.18(1)$ & Farm \\
\hline Quality assurance system of compound feed manufacturers & $3.92(2)$ & Farm \\
\hline Action in case of doubt about the withdrawal period & $3.39(3)$ & Farm \\
\hline Procedures and instructions for compound feed production & $3.13(4)$ & Feed \\
\hline Origin of forage & $3.10(5)$ & Farm \\
\hline Quality assurance system of feed ingredient manufacturers & $3.09(6)$ & Feed \\
\hline Best farm practices performance & $2.90(7)$ & Farm \\
\hline Water used for watering cows and production purposes & $2.83(8)$ & Farm \\
\hline Adequate cleaning and disinfection (feed manufacturer) & $2.74(9)$ & Feed \\
\hline Sourcing raw milk (dairy processing factory) & $2.70(10)$ & Dairy processing \\
\hline Quality assurance system of compound feed transporter & $2.69(11)$ & Farm \\
\hline Finished compound feed identification and traceability & $2.66(12)$ & Feed \\
\hline Reuse of water for cleaning and disinfection & $2.66(12)$ & Farm \\
\hline Feed ingredient identification and traceability & $2.62(13)$ & Feed \\
\hline Delivered raw milk identification and traceability & $2.61(14)$ & Dairy processing \\
\hline Total for the 15 attributes & 45.22 & \\
\hline \multicolumn{3}{|l|}{ Microbiological hazards $(\mathrm{k}=95)^{1}$} \\
\hline Manure supply source & $1.73(1)$ & Farm \\
\hline Action in salmonellosis and $M$. paratuberculosis cases & $1.71(2)$ & Farm \\
\hline Acquisition of cattle & $1.68(3)$ & Farm \\
\hline Udder cleaning before milking & $1.64(4)$ & Farm \\
\hline Calves feeding before weaning & $1.62(5)$ & Farm \\
\hline Finished product identification and traceability & $1.58(6)$ & Dairy processing \\
\hline Location of sealing equipment & $1.58(6)$ & Dairy processing \\
\hline General/personal hygiene conditions on the farm & $1.54(7)$ & Farm \\
\hline Quality assurance system of pasteurized milk manufacturers & $1.54(7)$ & Consumer \\
\hline Storage of pasteurized milk (consumption at home) & $1.52(8)$ & Consumer \\
\hline Maintenance of the equipment and leakage prevention & $1.49(9)$ & Dairy processing \\
\hline Maintenance of the equipment (retailer/catering establishment) & $1.46(10)$ & Consumer \\
\hline Place of calving & $1.45(11)$ & Farm \\
\hline Veterinary checks of cattle & $1.44(12)$ & Farm \\
\hline Best farm practices performance & $1.43(13)$ & Farm \\
\hline Total for the 15 attributes & 23.41 & \\
\hline
\end{tabular}

${ }^{1} \mathrm{k}$ represents the number of attributes per case.

\section{Analysis of Entire Chain}

Table 6 shows 15 attributes that are perceived by experts to be the most important for improving food safety along the entire dairy production chain for chemical as well as for microbiological cases.

According to Table 6, results for the chemical case reveal the importance of the specific attributes related to the "feed" and "farm" blocks. Additionally, the attributes "sourcing raw milk at dairy processing factory" and "delivered raw milk identification and traceability" indirectly show the importance of the "farm" block. Though these 2 attributes refer to the dairy processing level, they include measures aimed at assuring safe raw-milk production at the farm level. The 15 most important attributes account for $45 \%$ of importance of the 50 considered attributes (3 highest ranked attributes-11\%) (Table 6). This implies that dealing in a proper way with these top 15 attributes contributes considerably to improving food safety with respect to chemical hazards.
For the control of microbiological hazards, the results of Table 6 indicate that the most important attributes for the control of microbiological hazards are from the "farm" and "dairy processing" blocks. The top 15 attributes include $23 \%$ of importance of the 95 considered attributes. Moreover, the difference in importances among these attributes is rather small. These results suggest that, in the current situation with respect to microbiological hazards, it is essentially important to consider more than just the top 15 attributes for improving food safety.

From a comparison between the results for chemical and microbiological cases it can be inferred that the attributes relating to chain participants' quality assurance systems are perceived to be fairly important, especially for the chemical case. Examples include "quality assurance system of compound feed manufacturers" for the chemical case, and "quality assurance system of pasteurized milk manufacturers" for the microbiological case. Also, the attributes relating to traceability systems of chain participants are believed to be quite 
important in both cases. Examples are "finished compound feed identification and traceability", "delivered raw milk identification and traceability" for the chemical case, and "finished product identification and traceability" at the raw milk processing level for the microbiological case. These results imply that individual chain participants attach a high importance to the products supplied by the preceding chain participants. At the same time, results indicate that the attribute "best farm practices performance" is also rather important for both cases. In particular, this attribute includes requirements for feed and animal traceability, milking of cows, the storage and use of antibiotics, and general farmer education and training by certified persons.

\section{Significance of Results}

As shown in the previous sections, results per block detected statistically significant differences between means of some attributes' importances for chemical and microbiological cases of the "farm" block and for the microbiological case of the "dairy processing" block. A few aspects could affect the significance of the results for the other cases of the other blocks.

First, the rather small sample size could influence the statistical significance of the attributes' average relative importances per block, especially in the "feed" $(\mathrm{n}=4)$, "dairy processing" $(\mathrm{n}=5)$, and "consumer" $(\mathrm{n}=$ 2) blocks. Therefore, the tables showing the significance of the results per block were not included in this paper. The reasons for the low actual number of respondents can be explained. To begin with, only relatively few individuals could be approached to take part in the workshop, because the number of experts on food safety in the dairy chain in the Netherlands is somewhat limited. Also, some invited individuals may not have accepted the invitation because they did not consider themselves experts on the specified aspects of food safety within any part of the dairy chain. In addition, the participation in the workshop was time-consuming, as it included additional traveling in the evening. Though the low number of experts is explicable, it has major implications for the representativeness and reliability of the results, especially for the "consumer" block. Therefore, the results for these blocks are highly sensitive and limit the ability of the study to be the basis for generalization.

Second, the fact that the respondents for the "feed", "dairy processing", and "consumer" blocks did not show significant agreement among the rankings of attributes' importances could affect the obtained significance of the average results per block.

\section{CONCLUSIONS}

In conclusion, findings reported in this study present a comparable quantitative scale of various attributes' contribution to food safety improvement along the dairy production chain; however, they are the opinions of experts, and not facts about efficacy of control measures or any actual practices along the chain. Adaptive conjoint analysis turns out to be a helpful tool for eliciting the relative importance of the attributes for improving food safety. The results obtained refer to the chemical and microbiological hazards considered in this study. The applied approach provides some measurement of the total effect of both single- and multiple-effect attributes with respect to these hazards. However, without prior knowledge of the nature of the hazards, it is not possible to distinguish from the results whether the attribute has a single or a multiple effect.

From the described results with respect to the most important attributes for the whole dairy chain, it can be concluded that, according to experts' opinions, each block includes attributes that need more attention for improving food safety along the chain. The attributes from the "feed" and "farm" blocks are more vital for the control of chemical hazards, whereas the attributes from the "farm" and "dairy processing" are more vital for the control of microbiological hazards.

In addition, the relatively high importance of attributes relating to quality assurance and traceability systems of the dairy chain participants, both for individual blocks and the entire chain, suggests that chain participants are increasingly looking for food safety assurance from the participants preceding them in the chain. This is particularly true for the control of chemical hazards.

Despite the fact that the analysis is limited to the relatively small sample size, that the numbers of respondents per block varied, and that there was a possible bias with respect to the selection of the experts, outcomes of this research have substantial implications for decisions dealing with food safety improvement. The results allow prioritizing the more important attributes for each chain participant and the dairy chain as a whole. The more important attributes are interpreted to indicate where along the chain, implementation of control measures should be considered in the first place. This information helps chain participants to focus on the main attributes and to find ways (the right combination of control measures) to improve them as effectively as possible. In formulating policies regarding development of new food safety regulations, production practices and quality assurance schemes, similar information is needed. Moreover, utilizing the results of this study can be used to design extension education pro- 
grams aimed at improving food safety on the farm and other parts of the chain.

\section{ACKNOWLEDGMENTS}

This research was funded by the Dutch insurance company Achmea, dairy processing company Campina, and the Mesdagfonds foundation. The authors thank Ivo van der Lans (Marketing and Consumer Behavior Group, Wageningen University) for his contribution to the development of the ACA questionnaires.

\section{REFERENCES}

ACA User Manual System. 2002. Version 5 Sawtooth Software, Inc., Sequim, WA.

Churchill, G. A. 1999. Marketing Research. Methodological Foundations. 7th ed. The Dryden Press, Fort Worth, TX.

Collins, M. T. 1997. Mycobacterium paratuberculosis: A potential food-borne pathogen? J. Dairy Sci. 80:3445-3448.

Cullor, J. S. 1995a. Common pathogens that cause foodborne disease: Can they be controlled on the dairy? Vet. Med. 90:185-194.

Cullor, J. S. 1995b. Implementing the HACCP program on your clients' dairies. Vet. Med. 90:290-295.

Cullor, J. S. 1997. HACCP (Hazard Analysis Critical Control Points): Is it coming to the dairy? J. Dairy Sci. 80:3449-3452.

European Commission. 2000. White Paper on Food Safety. COM1999719 Final. European Commission, Brussels, Belgium. Online. Available: http://europa.eu.int/comm/dgs/health_consumer/ library/pub/pub06_en.pdf. Accessed Jan. 6, 2005.

Field, A. 2002. Discovering Statistics Using SPSS for Windows. SAGE Publications Ltd., London, UK.

Gould, B. W., M. Smukowski, and J. R. Bishop. 2000. HACCP and the dairy industry: An overview of international and US experiences. Pages 365-384 in The Economics of HACCP: Costs and Benefits. L. J. Unnevehr, ed. Eagan Press, St. Paul, MN.

Green, P. E., A. M. Krieger, and M. K. Agarwal. 1991. Adaptive conjoint analysis: Some caveats and suggestions. J. Mark. Res. $28: 215-222$
Green, P. E., and V. Srinivasan. 1990. Conjoint analysis in marketing: New developments with implications for research and practice. J. Mark. 54:3-19.

Huber, J. C., D. R. Wittink, J. A. Fiedler, and R. L. Miller. 1991. An empirical comparison of ACA and full profile judgments. Pages 189-202 in Proc. Sawtooth Software Conf., M. Metegrano, ed., Ketchum, ID. Sawtooth Software, Inc., Sequim, WA.

Jensen, H. H., and L. J. Unnevehr. 2000. HACCP in pork processing: Costs and benefits. Pages 29-44 in The Economics of HACCP: Costs and Benefits. L. J. Unnevehr, ed. Eagan Press, St. Paul, MN.

Jonson, R. M. 1987. Adaptive conjoint analysis. Pages 253-265 in Proc. Sawtooth Software Conf., Ketchum, ID. Sawtooth Software, Inc., Sequim, WA.

Jonson, R. M. 1991. Comment on "Adaptive conjoint analysis: Some caveats and suggestions". J. Mark. Res. 28:223-225.

Mathews, K. H., J. C. Buzby, L. R. Tollefson, and D. A. Dargatz. 2001. Livestock drugs: More questions than answers? Agric. Outlook September:18-21. Online. Available: http://www.ers.usda.gov/ publications/AgOutlook/sep2001/ao284g.pdf. Accessed Jan. 6, 2005.

Ollinger, M. E., and N. Ballenger. 2003. Weighing incentives for food safety in meat and poultry. Amber Waves 1(2):34-41. Online. Available: http://www.ers.usda.gov/Amberwaves/April03/pdf/ April2003.pdf. Accessed Jan. 6, 2005.

Sischo, W. M., N. E. Kiernan, C. M. Burns, and L. I. Byler. 1997. Implementing a quality assurance program using a risk assessment tool on dairy operations. J. Dairy Sci. 80:777-787.

Stefan, G. 1997. Food safety issues affecting the dairy beef industry. J. Dairy Sci. 80:3458-3462.

Valeeva, N. I., M. P. M. Meuwissen, and R. B. M. Huirne. 2004. Economics of food safety in chains: Review of general principles. Neth. J. Agric. Sci. 51:369-390.

Veling, J., H. Wilpshaar, K. Frankena, C. Bartels, and H. W. Barkema. 2002. Risk factors for clinical Salmonella enterica subsp. enterica serovar Typhimurium infection on Dutch dairy farms. Prev. Vet. Med. 54:157-168.

Wittink, D. R., and T. Bergestuen. 1999. Forecasting with conjoint analysis. Pages 145-168 in Principles of Forecasting: A Handbook for Researchers and Practitioners. J. S. Armstrong, ed. Kluwer Academic Publishers, Norwell, MA.

Wittink, D. R., M. Vries, and W. Burhenne. 1994. Commercial use of conjoint analysis in Europe: Results and critical reflections. Int. J. Res. Mark. 11:41-52. 